\title{
Statistical Modeling for the Extraction of Dye from Natural Source and Industrial Applications
}

\author{
Sobia Jabeen ${ }^{1}$, Shaukat Ali ${ }^{1}$, Muhammad Nadeem ${ }^{2}$, Khalid Arif ${ }^{3}$, Naseem Qureshi ${ }^{4}$, \\ Ghulam Abbas Shar ${ }^{5}$, Gul Afshan Soomro5, Munawar Iqbal ${ }^{6}$, Arif Nazir**, \\ Umme Habibah Siddiqua ${ }^{7}$ \\ ${ }^{1}$ Department of Chemistry, University of Agriculture, Faisalabad-Pakistan \\ ${ }^{2}$ Sharif College of Engineering \& Technology, Lahore-Pakistan \\ ${ }^{3}$ Department of Mathematics \& Statistics, University of Lahore, Lahore-Pakistan \\ ${ }^{4}$ Department of Chemistry, Karakoram International University, Gilgit, Gilgit-Pakistan \\ ${ }^{5}$ Institute of Chemistry, Shah Abdul Latif University, Khairpur, Sindh-Pakistan \\ ${ }^{6}$ Department of Chemistry, University of Lahore, Lahore-Pakistan \\ ${ }^{7}$ Department of Chemistry, University of Gujrat, Rawalpindi Campus, Rawalpindi-Pakistan
}

Received: 17 January 2018

Accepted: 7 February 2018

\begin{abstract}
This study is intended to scrutinize the consequence of extraction conditions of Lawsonia Inermis (henna) leaves on the color strength values of dyed fabric. Extraction $\mathrm{pH}, \mathrm{M}: \mathrm{L}$ ratio, and time were optimized using central composite design (CCD) under response surface methodology (RSM). We investigated how the maximum colour strength values were obtained at $\mathrm{pH} 6.64$ in about 78 minutes extraction with an M:L ratio of 1:44. ANOVA results showed that all the extraction parameters significantly affect the colour strength values of dyed samples. $99 \%$ variation in the response was indicated in the $2^{\text {nd }}$-order regression equation for K/S. The fastness properties with respect to light, washing, and rubbing were quite satisfactory of dyed samples under optimized extraction conditions.
\end{abstract}

Keywords: central composite design, henna leaves, natural dye, response surface methodology, extraction

\section{Introduction}

Beautiful and attractive displays of the color of nature have captivated our attention since prehistoric times. In ancient times humans used natural resources (plants, animals, and minerals) to extract dye or colorant and used them for dyeing textile fibers and ornamental

*e-mail: anmalik77@gmail.com purposes, thus marking the start of a colorful lifestyle [1]. However, in the mid-18th century the innovation of synthetic dye (Mauveine) completely replaced the use of natural dyes [1-2]. These dyes were cheap and give a bright reproducible range of colors and have excellent fastness properties [2-3]. Synthetic dyes are widely used in various industries, e.g., textile, leather, petroleum, and wood protective chemicals [4]. However, large amounts of effluents released from textile or leather industries are directly wasted in the water, where it causes water 
pollution. About $10-35 \%$ of the dye is wasted in the water during the dyeing process [5-18]. Therefore environmental pollution due to synthetic dyes is a severe problem due to their pessimistic effect on the ecosystem and bioaccumulation in flora and fauna [19]. Water pollution due to synthetic dyes affects the environment and has detrimental impacts on living organisms [20-21]. Due to the negative aspects of these dyes, people have been moving toward natural dyes as they are less harmful, environmentally friendly, and have colorful eye-catching shades. Natural dyes have considerably reduced the amount of poisonous waste released due to dyeing methods and they have successfully replaced synthetic dyes.

Natural dyes are acquired from different sources including plants and animals without the application of any chemical handling. This group of dyes is documented to be eco-friendly and slightly poisonous as compared to synthetic dyes [22-24]. However, it has been reported that some natural dyes may cause mutagenic effects such as safflower yellow, and elderberry color and continuous inhalation of carmine can cause asthma, but it can be said that some even have a curative impact such as turmeric with its antibacterial properties due to its coloring component, curcumin [25-30].

Lawsonia inermis $L$., generally known as henna, is a small plant commonly cultivated in Iran, India, Egypt, and Pakistan. The aqueous paste of powdered leaves of the plant is employed for coloring hair and hands. Basically it contains lawsone, i.e., red-orange pigment (also known as hennotannic acid - the chief constituent of henna leaves). The dyeing, UV absorption, and corrosion inhibition characteristics of henna leaves are associated with the presence of lawsone (2- hydroxy-1, 4-naphthoquinone) [31-34]. For keratin, lawsone acts as a substantive dye and produces orange color due to the presence of the hydroxyl group in naphthoquinone structure [34-35].

It is quite important to optimize extraction conditions in order to obtain maximum coloring components solubilized into solvent. There were three main factors with different levels to evaluate the interactions among the factors by the approach of an experimental design. RSM is a statistical approach for the optimization process as compared to full-factorial approach [36]. CCD is a very reliable model fitting tool of RSM and was used to recognize the connection between yield and all the process variables such as extraction $\mathrm{pH}$, extraction time, and M:L [37-39]. The purpose of this investigation was to examine the outcomes of different extraction parameters, i.e., $\mathrm{pH}$, time, and material to liquor ratio on the extraction of natural dye from henna leaves.

\section{Material and Methods}

The sample was obtained from the botanical garden at the University of Agriculture in Faisalabad, Pakistan.
Table 1. Experimental variable and their levels.

\begin{tabular}{|c|c|c|c|c|c|}
\hline \multirow{2}{*}{ Variables } & \multicolumn{5}{|c|}{ Levels } \\
\cline { 2 - 6 } & - alpha & -1 & 0 & +1 & + alpha \\
\hline $\mathrm{pH}$ & 2 & 4 & 7 & 10 & 12 \\
\hline Time (min.) & 30 & 42 & 60 & 78 & 90 \\
\hline M:L & 20 & 26 & 35 & 44 & 50 \\
\hline
\end{tabular}

After washing and drying the leaves at about $37-40^{\circ} \mathrm{C}$, the leaves were crushed to fine powder of uniform particle size that can pass through 25 mesh size. This powdered material was employed for extraction under different conditions.

On the basis of previous studies and initial trials, we identified three experimental variables for study, including $\mathrm{pH}$ of extraction, time of extraction, and ratio between material and liquor (M:L). The data is recorded in Table 1. In this experimental design, low and high levels are designated by -alpha and +alpha, respectively. The axial points are positioned at a distance of $\alpha$ (alpha) from central point and thus make the design rotatable [40].

The relationship between the experimental variables $(\mathrm{pH}$, extraction time, and $\mathrm{M}: \mathrm{L})$ and response variable of color strength values $(\mathrm{K} / \mathrm{S})$ of cotton fabric dyed at different extraction conditions) was developed by two level-three factor $\left(2^{3}\right)$ full factorial CCD in RSM. The statistical software package, design-expert 7.0, was used to design experimental conditions (Table 2).

Reflux boiling methodology was used to extract natural dye from henna leaves in distilled water. $5 \mathrm{~g}$ powdered sample were added in round-bottomed flasks and $\mathrm{pH}$ of the extraction liquors was adjusted. The extract from the sample was taken at different time spans $(30,42,60,78$, and $90 \mathrm{~min})$ and different L:R (Table 2). Bleached cotton fabric was dyed by following the method given in Ali et al. [41]. The dyed cotton samples were then washed and air-dried under the shade. The colour strength $(\mathrm{K} / \mathrm{S})$ values of dyed samples were measured by the method described in Kannan et al. [42].

Most dyes are organic compounds that can be affected by natural destructive agents that can fade and destroy these colours. This is further supported by the use of certain chemicals used in finishing treatments that may affect the fastness properties of dyed fabrics. Washing fastness (ISO 105-CO2method), rubbing fastness (ISO 105-X12 method), and light fastness (ISO-B-02) tests were performed to evaluate fastness properties.

\section{Results and Discussion}

Table 2 shows the colour strength values of fabric dyed extracted material from leaves of henna under different experimental/extraction conditions. 
Table 2. Colour strength $(\mathrm{K} / \mathrm{S})$ values under different extraction conditions.

\begin{tabular}{|c|c|c|c|c|}
\hline S. No. & $\mathrm{pH}$ & $\begin{array}{l}\text { Time } \\
(\mathrm{min})\end{array}$ & $\begin{array}{l}\mathrm{M}: \mathrm{L} \\
(\mathrm{ml})\end{array}$ & $\mathrm{K} / \mathrm{S}$ \\
\hline 1 & 7 & 60 & 35 & 6.5 \\
\hline 2 & 10 & 42 & 26 & 5.7 \\
\hline 3 & 12 & 60 & 35 & 4.3 \\
\hline 4 & 7 & 60 & 35 & 6.5 \\
\hline 5 & 4 & 42 & 26 & 6.4 \\
\hline 6 & 10 & 42 & 43 & 5 \\
\hline 7 & 7 & 30 & 35 & 6.2 \\
\hline 8 & 7 & 60 & 20 & 6.9 \\
\hline 9 & 2 & 60 & 35 & 5 \\
\hline 10 & 7 & 90 & 35 & 7 \\
\hline 11 & 10 & 78 & 44 & 5.9 \\
\hline 12 & 7 & 60 & 35 & 6.5 \\
\hline 13 & 7 & 60 & 35 & 6.5 \\
\hline 14 & 4 & 78 & 44 & 6.5 \\
\hline 15 & 10 & 78 & 26 & 6.1 \\
\hline 16 & 4 & 42 & 44 & 6 \\
\hline 17 & 4 & 78 & 26 & 6.2 \\
\hline 18 & 7 & 60 & 35 & 6.5 \\
\hline 19 & 7 & 60 & 35 & 6.5 \\
\hline 20 & 7 & 60 & 50 & 6.7 \\
\hline
\end{tabular}

A higher K/S magnitude indicates higher dye extraction proficiency. The analysis of variance (ANOVA) results (Table 3) show that the model is significant with p-value less than 0.0001, and all terms are significant except $\mathrm{B}^{2}$.

The $2^{\text {nd }}$-order quardatic equation for colour strength is given as follows:

$\mathrm{K} / \mathrm{S}=+6.50-0.26 \mathrm{~A}+0.22 \mathrm{~B}-0.098 \mathrm{C}+0.13 \mathrm{AB}$

$-0.100 A C+0.15 B C-0.66 A^{2}+0.033 B^{2}+0.10 C^{2}$

The process parameters $\mathrm{pH}$, time, and $\mathrm{M}: \mathrm{L}$ are designated as $\mathrm{A}, \mathrm{B}$, and $\mathrm{C}$, respectively. The positive and negative signs with each term exhibit synergistic and antagonistic effects, respectively. The $\mathrm{R}^{2}$ value (0.9941) indicates that $99 \%$ change in colour strength can be explained by the terms included in the equation, and only $0.59 \%$ of the variance was not explained by the equation.

Fig. 1a) displays the effect of $\mathrm{pH}$ and extraction duration on strength of colour on the dyed fabric (cotton). $\mathrm{pH}$ plays a significant role in the extraction of coloring component from natural dyes. Initially for the experimental set up, the acidity and alkalinity levels were adjusted by employing $0.1 \mathrm{M} \mathrm{HCl}$ and $0.1 \mathrm{M} \mathrm{NaOH}$, accordingly. $\mathrm{pH}$ was not significantly altered after initial adjustment as the original $\mathrm{pH}$ of henna leaves was found to be neutral. Although color strength of dye extracts obtained in distilled water is not appreciable, maximum color strength in distilled water was obtained at $\mathrm{pH} 6.46$ - approximately near neutral. Because the coloring component of henna dye is acidic hydroxylated (a-hydroxynaphthaquinone) [42], color strength values decrease in acidic $\mathrm{pH}$ while hydroxy-naphthaquinone

Table 3. ANOVA for colour strength.

\begin{tabular}{|c|c|c|c|c|c|}
\hline Source & Sum of Squares & Mean df Square value & FP Value & Prob $>F$ & Remarks \\
\hline Model & 8.82 & 9 & 0.98 & 186.80 & $<0.0001 \quad$ significant \\
\hline A-pH & 0.94 & 1 & 0.94 & 178.67 & $<0.0001$ \\
\hline B-Time & 0.64 & 1 & 1 & 121.13 & $<0.0001$ \\
\hline C-M:L & 0.13 & 1 & 1 & 24.93 & 0.0005 \\
\hline $\mathrm{AB}$ & 0.13 & 1 & 1 & 23.83 & 0.0006 \\
\hline $\mathrm{AC}$ & 0.080 & 1 & 0.080 & 15.25 & 0.0029 \\
\hline $\mathrm{BC}$ & 0.18 & 1 & 0.18 & 34.32 & 0.0002 \\
\hline$A^{2}$ & 6.21 & 1 & 6.21 & 1184.96 & $<0.0001$ \\
\hline $\mathrm{B}^{2}$ & 0.015 & 1 & 0.015 & 2.95 & 0.1168 \\
\hline $\mathrm{C}^{2}$ & 0.15 & 1 & 0.15 & 29.41 & 0.0003 \\
\hline Residual & 0.052 & 10 & $5.245 \mathrm{E}-003$ & & \\
\hline Lack of Fit & 0.052 & 5 & 0.010 & & Insignificant \\
\hline Pure Error & 0.000 & 5 & 0.000 & & \\
\hline Cor Total & 8.87 & 19 & & & \\
\hline
\end{tabular}



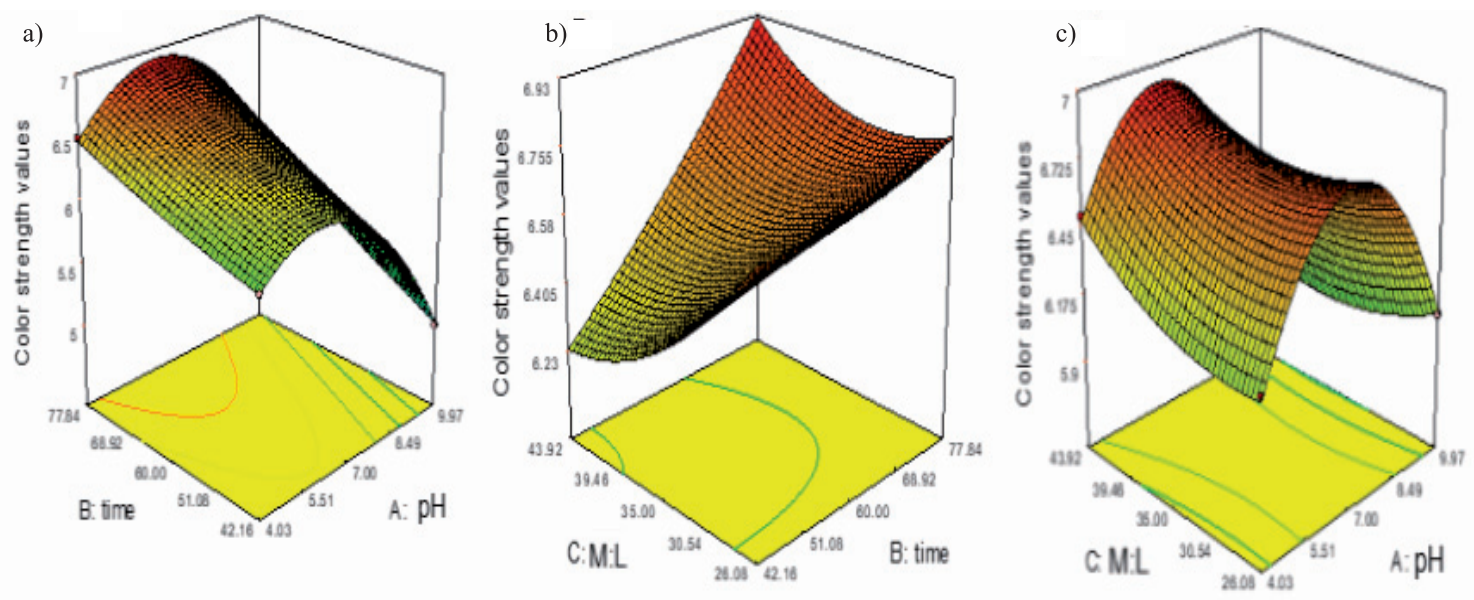

Fig. 1. Effect of extraction a) $\mathrm{pH}$ and time, b) time and $\mathrm{M}: \mathrm{L}$, and c) $\mathrm{pH}$ and $\mathrm{M}: \mathrm{L}$ on color strength (K/S).

have high reactivity at basic $\mathrm{pH}$ due to which coloring components have strong interaction with the solvent and transfer of coloring component toward the cotton fabric is reduced, whereby colour strength values also decrease at basic $\mathrm{pH}$.

The K/S values increase with extraction span and touch a maximum value at 78 minutes. This might be due to the fact that as the extraction time increased, the interaction between plant materials and extracting solvent increased, hence leading to increased yield of natural dye in extraction media. It can be concluded from the results that the $K / S$ values were highly dependent on extraction time. However, further increases in extraction time resulted in decreases in colour strength values due to the decomposition of the coloring component [43].

Fig. 1b) shows the extraction time and M:L effect on color strength of dyed fabric. A low M:L (1:44) ratio was found to be appropriate for higher colour strength. Increasing $\mathrm{M}: \mathrm{L}$ ratios caused a decrease in extraction of the required component. Low M:L ratio and longer extraction time improved the extraction of the coloring component from henna. This comment can be associated with the idea that the saturation point of the colouring component was achieved at initial M:L ratio.

Fig. 1c) shows the effect of $\mathrm{pH}$ and $\mathrm{M}: \mathrm{L}$ on $\mathrm{K} / \mathrm{S}$ of the dyed cotton fabric. Colour strength was high at neutral $\mathrm{pH}$ and at low M:L ratio. The significant decrease in colour yield by increasing the M:L from 44 to 78 was also supported by ANOVA results.

The colour fastness to washing, light, and rubbing (dry and wet) of the dyed fabric with the optimized extract of henna leaves was 4, 4-5, 4-5, and 3-4, respectively. Colour fastness to various parameters was found to be good. The superior washing fastness properties of the colorant might be owing to the affinity of colouring component caused by hydrogen bonding and Vander Waals forces for the dyed sample. The light fastness of the dye was fairly good due to hydrogen bonding between the hydroxyl and carbonyl groups of naphthaquinone, hence shielding the chromophoric group from fading [44-50]. The fastness with respect to light washing and rubbing were satisfactory of dyed samples at optimized extraction conditions and the technique was ecofriendly and could be used to reduce pollution [51-57].

\section{Conclusions}

RSM has been used to make a model of colour strength values of dyed samples with henna leaves extract. ANOVA showed that extraction $\mathrm{pH}$, extraction time, and $\mathrm{M}: \mathrm{L}$ have a significant impact on colour strength values. The values of the optimized factors of extraction for henna leaves are: $\mathrm{pH}$ 6.64, M:L 1:44 ml, and extraction time 78 minutes. The $\mathrm{pH}$ of the solution markedly influenced the dye extraction from dried henna leaves and found maximum at $\mathrm{pH}$ 6.46, while extraction time and M:L are also statistically significant. Dyed samples not only show good colour strength values but also show good fastness properties without using any mordant.

\section{Conflict of Interest}

The authors declare no conflict of interest.

\section{References}

1. SINGH K., ARORA S. Removal of synthetic textile dyes from wastewaters: a critical review on present treatment technologies. Crit. Rev. Environ. Sci. Technol. 41, 807, 2011.

2. LEITNER P., FITZ-BINDER C., MAHMUD-ALI A., BECHTOLD T. Production of a concentrated natural dye from Canadian Goldenrod (Solidago canadensis) extracts. Dyes Pigments. 93, 1416, 2012.

3. ZARKOGIANNI M., MIKROPOULOU E., VARELLA E., TSATSARONI E. Colour and fastness of natural dyes: revival of traditional dyeing techniques. Coloration Technol. 127, 18, 2010. 
4. BENABDALLAH N.K., HARRACHE D., MIR A., DE LA GUARDIA M., BENHACHEM F.-Z. Bioaccumulation of trace metals by red alga Corallina elongata in the coast of Beni Saf, west coast, Algeria. . Chem. Int. 3, 220, 2017.

5. DAGNAW W., MEKONNEN A. Preliminary phytochemical screening, isolation and structural elucidation of chloroform leaf extracts of Maesa lanceolata. Chem. Int. 3, 251, 2017.

6. ENGIDA A.M., CHANDRAVANSHI B.S. Assessment of heavy metals in tobacco of cigarettes commonly sold in Ethiopia. Chem. Int. 3, 213, 2017.

7. FAIT S., FAKHI S., ELMZIBRI M., FAIZ Z., FOUGRACH H., BADRI, W., SMOUNI A., FAHR M. Distribution of metallic trace elements (ETM) in surface soils around the mediouna discharge (southern of Casablanca). Chem. Int. 3, 278, 2017.

8. JAFARINEJAD S. Activated sludge combined with powdered activated carbon (PACT process) for the petroleum industry wastewater treatment: A review. Chem. Int. 3, 268, 2017.

9. LEGROURI K., KHOUYA E., HANNACHE H., EL HARTTI M., EZZINE M., NASLAIN R. Activated carbon from molasses efficiency for $\mathrm{Cr}(\mathrm{VI}), \mathrm{Pb}(\mathrm{II})$ and $\mathrm{Cu}(\mathrm{II})$ adsorption: A mechanistic study. Chem. Int. 3, 301, 2017.

10. MAJOLAGBE A.O., ADEYI A.A., OSIBANJO O., ADAMS A.O., OJURI O.O. Pollution vulnerability and health risk assessment of groundwater around an engineering Landfill in Lagos, Nigeria. Chem. Int. 3, 58, 2017.

11. QAMAR A., ASI R., IQBAL M., NAZIR A. Survey of Residual Pesticides in Various Fresh Fruit Crops: A Case Study. Pol. J. Environ. Stud. 26 (6), 2703, 2017.

12. MUNIR A., SULTANA B., BASHIR A., GHAFFAR A., MUNIR B., SHAR G.A., NAZIR A., IQBAL M. Evaluation of Antioxidant Potential of Vegetables Wastes. Pol. J. Environ. Stud. 27 (2), 947, 2018.

13. HASSAN S.M., IQBAL M., BUKHARI T.H., NISAR N., TAHIR M.A., ABBAS M., KANWAL Q., IQBAL D.N., NAZIR A. Fungal infestation and aflatoxins synthesis control in stored poultry feed using medicinal plants. Environ. Technol. Innovt. 7, 194, 2017.

14. IQBAL M. Vicia faba bioassay for environmental toxicity monitoring: a review. Chemosphere 144, 785, 2016.

15. IQBAL M., ABBAS M., ARSHAD M., HUSSAIN T., KHAN A.U., MASOOD N., TAHIR M.A., HUSSAIN S.M., BOKHARI T.H., KHERA R.A. Gamma radiation treatment for reducing cytotoxicity and mutagenicity in industrial wastewater. Pol. J. Environ. Stud. 24, 2745, 2015.

16. IQBAL M., BHATTI I.A. Gamma radiation $/ \mathrm{H}_{2} \mathrm{O}_{2}$ treatment of a nonylphenol ethoxylates: degradation, cytotoxicity, and mutagenicity evaluation. J Hazard. Mater. 299, 351, 2015.

17. IQBAL M., NISAR J. Cytotoxicity and mutagenicity evaluation of gamma radiation and hydrogen peroxide treated textile effluents using bioassays. J. Environ. Chem. Eng. 3, 1912, 2015.

18. IQBAL M., NISAR J., ADIL M., ABBAS M., RIAZ M., TAHIR M.A., YOUNUS M., SHAHID M. Mutagenicity and cytotoxicity evaluation of photo-catalytically treated petroleum refinery wastewater using an array of bioassays. Chemosphere 168, 590, 2017.

19. SAHA P., CHOWDHURY S., GUPTA S., KUMAR I. Insight into adsorption equilibrium, kinetics and thermodynamics of Malachite Green onto clayed soil of Indian origin. J. Chem. Eng. 165 (1), 874, 2010.
20. KIRAN I., ILHAN S., CANER N., ISCEN C.F., YILDIZ Z. Biosorption properties of dried Neurospora crassa for the removal of Burazol blue ED dye. J. Desalinat. 249, 273, 2009.

21. AKAR S.T., OZCAN A.S., AKAR T., OZCAN A., KAYNAK Z. Biosorption of a reactive textile dye from aqueous solutions utilizing an agro-waste. Desalination 249 (1), 757, 2009.

22. TIWARI V., VANKAR P.S. Unconventional natural dyeing using microwave and sonicator with alkanet root bark. J. Colourage 48 (2), 25, 2001.

23. BHUYAN R., SAIKIA C.N., DAS K.K. Extraction and identification of colour components from the bark of Mimusops elengi and Terminalia arjuna and evaluation of their dyeing characteristics on wool. Indian J. Fibre Textile Res. 29, 470, 2004.

24. GUPTA D., KUMARI S., GULRAJANI M. Dyeing studies with hydroxyanthraquinones extracted from Indian madder. Part 2. Dyeing of nylon and polyester with nordamncanthal. Color. Technol. 11, 333, 2001.

25. HAN S., YANG Y. Antimicrobial activity of wool fabric treated with curcumin. Dyes Pigments. 64 (2), 157, 2005.

26. NOUREN S., BHATTI H.N., IQBAL M., BIBI I., NAZAR N., IQBAL D.N., KANWAL Q., KAUSAR A., HUSSAIN F. Redox Mediators Assisted-degradation of Direct Yellow 4. Pol. J. Environ. Stud. 26 (6), 2885, 2017.

27. ULLAH I., ALI S., HANIF M.A., ZIA M.A. Photocatalytic Activity of A12O3.Fe2O3 Synthesized by UltrasonicAssisted Mechanical Stirring. Pol. J. Environ. Stud. 26 (6), 2777, 2017.

28. KONICKI W., SIBERA D., NARKIEWICZ U. Adsorption of Acid Red 88 Anionic Dye from Aqueous Solution onto $\mathrm{ZnO} / \mathrm{ZnMn} 2 \mathrm{O} 4$ Nanocomposite: Equilibrium, Kinetics, and Thermodynamics. Pol. J. Environ. Stud. 26 (6), 2585, 2017.

29. SIDDIQUA U.H., ALI S., HUSSAIN T., BHATTI H.N., ASGHAR M. The Dyeing Process and the Environment: Enhanced Dye Fixation on Cellulosic Fabric Using Newly Synthesized Reactive Dye. Pol. J. Environ. Stud. 26 (5), 2215, 2017.

30. NOREEN S., BHATTI H.N., ZUBER M., ZAHID M., ASGHER M. Removal of Actacid Orange-RL Dye Using Biocomposites: Modeling Studies. Pol. J. Environ. Stud. 26 (5), 2125, 2017.

31. AL-SEHAIBANI H. Evaluation of extraction of Henna leaves as environmentally friendly corrosion inhibitor for metals. Materialwissenschaft und Werkstofftechnik 31 (12), 1060, 2000.

32. DWECK A.C. Natural ingredients for colouring and styling. Int. J. Cosmetic Sci. 24 (5), 287, 2002.

33. NAUSHEEN S., BHATTI H.N., HANIF M.A., REHMAN K. Enhanced Removal of Golden XGL Dye by Clay Composites: Batch and Column Studies. Pol. J. Environ. Stud. 26 (5), 2113, 2017.

34. MONDAL M.I.H., SAYEED M.A., NEWAZ M.O., SALAM M.A. Isolation of a natural dye isolated from the leaves of Lawsonia inermis Linn. and its dyeing characteristics onto silk. Colourage 57 (7), 52, 2009.

35. BECHTOLD T. Natural colorants e quinoid, naphthoquinoid and anthraquinoid dyes. In: Bechtold, T., Mussak, R. (Eds.), Handbook of Natural Colorants. John Wiley \& Sons Ltd., UK, 153, 2009.

36. JAOUACHI B., HASSEN M.B., SAKLI F. Strength of wet spliced denim yarns after sizing a central composite design. Autex Res. J. 7, 3, 2007. 
37. SUN Q., XIAO W., XI D., SHI J., YAN X., ZHOU Z. Statistical optimization of biohydrogen production from sucrose by a co-culture of Clostridium acidisoli and Rhodobactersphaeroides. Int. J. Hyd. Energ. 35, 4076, 2010.

38. BRANCHU S., FORBES R.T., YORK P., NIQVIST H. A central composite design to investigate the thermal stabilization of lysozyme. Pharmaceutical Research 16, 5, 1999.

39. GUO W.-Q., REN N.-Q., WANG X.-J., XIANG W.-S., DING J., YOU Y., LIU B.-F. Optimization of culture conditions for hydrogen production by Ethanoligenensharbinense B49 using response surface methodology, Bioresour. Technol. 100, 1192, 2009.

40. NASIRIZADEH N., DEHGHANIZADEH H., YAZDANSHENAS M.E., MOGHADAM M.R., KARIMI A. Optimization of wool dyeing with rutin as natural dye by central composite design method. Indus. Crops Prod. 40, 361, 2012.

41. ALI S., HUSSAIN T., NAWAZ R. Optimization of alkaline extraction of natural dye from Henna leaves and its dyeing on cotton by exhaust method. J. Clean. Prod. 17 (1), 61, 2009.

42. KANNAN M.S.S., GOBALAKRISHNAN M., KUMARAVEL S., NITHYANADAN R., RAJASHANKAR K.J., VADICHERALA T. Influence of cationization of cotton on reactive dye. J. Textile Apparel Technol. Manage. 5 (2), 1, 2006.

43. NAGIA F.A., EL-MOHAMEDY R.S.R. Dyeing of wool with natural anthraquinone dyes from Fusarium oxysporum. Dyes Pigments. 75 (3), 550, 2007.

44. CRISTEA D., VILAREM G. Improving light fastness of natural dyes on cotton yarn. Dyes Pigments. 70 (3), 238, 2006.

45. SULYMAN M., NAMIESNIK J., GIERAK A. Low-cost Adsorbents Derived from Agricultural By-products/Wastes for Enhancing Contaminant Uptakes from Wastewater: A Review. Pol. J. Environ. Stud. 26 (2), 479, 2017.

46. LI-HONG Y., YU-JUN W., LAN L., YUE-HUA Z. Univariate Degradation of Indigo Carmine in Aqueous Solution by Inactivated Biomass in Heterobasidion Insulare: Preliminary Studies. Pol. J. Environ. Stud. 25 (5), 2221, 2016.
47. AGUNBIAdE M.O., POHL C.H., ASHAFA A.O.T. A Review of the Application of Biofloccualnts in Wastewater Treatment. Pol. J. Environ. Stud. 25 (4), 1381, 2016.

48. PERMPORNSAKUL P., PRASONGSUK S., LOTRAKUL P., EVELEIGH D.E., KOBAYASHI D.Y., IMAI T., PUNNAPAYAK H. Biological Treatment of Reactive Black 5 by Resupinate White Rot Fungus Phanerochaete sordida PBU 0057. Pol. J. Environ. Stud. 25 (3), 1167, 2016.

49. KALKAN E., NADAROGLU H., CELEBI N., CELIK H., TASGIN E. Experimental Study to Remediate Acid Fuchsin Dye Using Laccase-Modified Zeolite from Aqueous Solutions. Pol. J. Environ. Stud. 24 (1), 115, 2015.

50. REGULSKA E., KARPIŃSKA J. Investigation of Photocatalytic Activity of $\mathrm{C} 60 / \mathrm{TiO}_{2}$ Nanocomposites Produced by Evaporation Drying Method. Pol. J. Environ. Stud. 23 (6), 2175, 2014.

51. MARKOVIC M., JOVIC M., STANKOVIC D., MUTIC J., ROGLIC G., MANOJLOVIC D.D. Toxicity Screening after Electrochemical Degradation of Reactive Textile Dyes. Pol. J. Environ. Stud. 23 (6), 2103, 2014.

52. QURESHI K., AHMAD M., BHATTI I., IQBAL M., KHAN A. Cytotoxicity reduction of wastewater treated by advanced oxidation process. Chem. Int. 1, 53, 2015.

53. SHINDY H. Basics in colors, dyes and pigments chemistry: A review. Chem. Int. 2, 29, 2016.

54. SHARMA S.K. Eco-friendly and fast bromination of industrially-important aromatic compounds in water using recyclable $\mathrm{AlBr} 3$-Br2 system. Chem. Int. 1, 60, 2015.

55. SHARMA S.K., AGARWAL D. A Direct and simplistic Bromination of commercially important organic compounds in aqueous media by eco-friendly AlBr3-Br2 reagent system. Chem. Int. 1, 106, 2015.

56. PERVAIZ M., BUTT K.M., RAZA M.A., RASHEED A., AHMAD S., ADNAN A. Extraction and applications of aluminum hydroxide from bauxite for commercial consumption. Chem. Int. 1, 99, 2015.

57. BILAL M., ASGHER M. Dye decolorization and detoxification potential of Ca-alginate beads immobilized manganese peroxidase. BMC Biotechnol. 15, 1, 2015. 